Prace Komisji Geografii Komunikacji PTG Transport Geography Papers of Polish

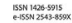

$21(4) / 2018$

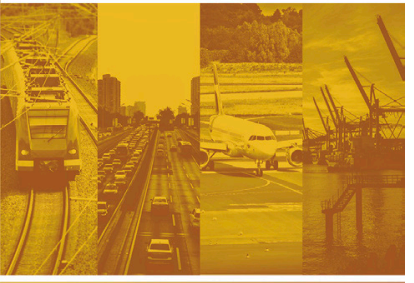

Transport Geography Papers of Polish Geographical Society

$2018,21(4), 7-13$

DOI 10.4467/2543859XPKG.18.019.10777

\title{
DRIVERLESS MOBILITY AND THE GEOGRAPHIC ANALYSIS OF CONTEMPORARY AUTONOMOUS VEHICLES STARTUP ECOSYSTEM
}

\section{Mobilność bez kierowcy i analiza geograficzna współczesnego ekosystemu startupów pojazdów autonomicznych}

\author{
Andrei Bezruchonak \\ Department of Economic and Social Geography, Faculty of Geography, Belarusian State University, Leningradskaya st. 16, 220030, Minsk, Belarus \\ E-mail: bezruchonak@bsu.by
}

\section{Citation:}

Bezruchoank A., 2018, Driverless mobility and the geographic analysis of contemporary autonomous vehicles startup ecosystem, Prace Komisji Geografii Komunikacji PTG, 21(4), 7-13.

\begin{abstract}
Over 50 billion US dollars had been invested into autonomous vehicles (AV) technology in 2013-2017. Driverless cars of the level 4 and 5 are forecasted to be in mass production after 2028 and the annual direct and indirect social and economic input of the AV technology is estimated to be over US \$1.8-2.8 trillion in 2030. The purpose of this paper is to analyze the geographic structure of AV startup ecosystem, which is considered as one of the most significant disruptive and gamechanging innovations of the nearest decades. The geographic analysis was carried out for $265 \mathrm{AV}$ tech companies and startups, working on solutions to the following problem areas: services, infrastructure, in-car assistance and intelligence, safety, security, autonomy, sensors, materials and manufacturing. The key findings outline that the USA is the leader on the innovative AV market ecosystem (accounting for $57 \%$ of all startups) with the highest concentration near San Francisco Bay Area Core (more than $27 \%$ of all startups), followed up with a significant gap by Israel, India, UK and Canada. The main factors that define the level of readiness for autonomous vehicles, and, thus, the geography of diffusion of AVs innovation are regulatory and legislative environment, level of transportation and communication infrastructure development and public perception.
\end{abstract}

Keywords: autonomous vehicles, driverless cars, disruptive innovations, 3Rs in transportation, R\&D in transportation, Waymo, startups 


\section{Introduction}

According to the estimations of the Institute for Transportation \& Development Policy, the contemporary world is on the cusp of three revolutions in transportation: vehicle automation, electrification and shared mobility. The scenario considering all three trends produces impressive global results by 2050, like: a) cut of global energy use from urban passenger transportation by over $70 \%$; b) cut of $\mathrm{CO} 2$ emissions by over $80 \%$; c) cut the measured costs of vehicles, infrastructure, and transportation system operation by over $40 \%$; d) achieve savings approaching $\$ 5$ trillion per year Fulton et al., 2017.

Autonomous vehicles (AVs, driverless or self-driving cars, as used in this article) are motor vehicles that operate without a human driver, which reduces the cost of transportation and improves convenience and (in most cases) safety (PwC, 2016). The idea of driverless cars is not new. The first concepts can be traced back to General Motor's vision of the future of transportation system, presented at New York World's Fair in 1939 (Gogoll, Muller, 2016). The visions of unmanned vehicles have never disappeared completely, not in the corporate environments of manufacturing companies and military (i.e. DARPA projects - Grand Challenge of 2004 or Urban Challenge of 2007), nor in mass culture (i.e. in the movie entitled "Trucks" (1986) based on the story of Stephen King (1973) or in the recent episodes of X-Files and The Simpsons (2018)).

The current vision and progress of automotive technology to enable full vehicle automation has emerged rapidly after 2003, when the Defense Advanced Research Projects Aglency (DARPA) announced the competition entitled Grand Challenge. The goal of the competitions, organized in 2004 and 2005 was to develop autonomous vehicles capable of navigating desert trails and roads at high speeds (as a response to a congressional mandate that a third of U.S. military ground vehicles be unmanned by 2015). After the success of the Grand Challenges, DARPA organized a third event: the Urban Challenge. The challenge, announced in April 2006 and held in
2007, called for autonomous vehicles to drive $97 \mathrm{~km}$ through an urban environment, interacting with other moving vehicles and obeying the California Driver Handbook Urmson et al., 2008.

Since the DARPA Challenges, the idea of autonomous vehicles had experienced an unprecedented uptake with significant portions of excitement and attention (especially after accidents, usually caused by humans). There are several explanations to that, such as technological advancements (development and growing affordability of LiDAR (Light Detection and Ranging), improvement of radars and V2V (vehicleto-vehicle) and V2I (vehicle-to-infrastructure) connectivity) and significant R\&D support from major car manufacturers (i.e. BMW, Volvo, Mercedes, etc.) and tech companies (Google, Apple, etc.). In total, there are more than 265 major startups located in more than 31 country, that work in the areas related to autonomous driving in 2018 (with autonomy itself being only a part of a more complex system). Due to interest coming from corporations and companies, including the dominant vehicle manufacturers, technology giants and specialist startups, the development of AVs technology had attracted around US\$50 billion over 2013-2017, with $70 \%$ of the spending coming from outside the automotive sector (KPMG, 2018). The analysis of the $A V$ startup environment, given in part 5 of this article, proves it's structural and spatial complexity.

When it comes to AVs, it is important to emphasize that there are five defined levels of vehicle automation, according to the Society of Automotive Engineers and the National Highway traffic Safety Administration, briefly presented in table 1 . Levels 0,1 and 2 are widespread and been available for many years (i.e. cruise control - from 1960s, electronic stability control - since the 1990s, lane departure warning systems - since 2000s). Level 3 means limited self-driving, including hands-free driving. It is mostly in developing phase and only legal in some areas (i.e. in some states of the USA). The performance of Tesla Autopilot can be considered as a good case of Level 3 vehicle operation (the car can manage its velocity, follow the traffic lane and change the lanes, park itself, etc.).

Table 1. Levels of vehicles automatization

\begin{tabular}{|c|c|c|c|}
\hline Level & Autonomy & Driver's control & Geography and examples \\
\hline $0-1$ & No autonomy & Driver has control. Limited assistance. & \multirow{2}{*}{$\begin{array}{l}\text { Widespread, with features introduced by the } \\
\text { majority of car manufacturers (cruise control, } \\
\text { electronic stability control, etc.). }\end{array}$} \\
\hline 2 & $\begin{array}{l}\text { Vehicle gives driver } \\
\text { warnings and info }\end{array}$ & $\begin{array}{l}\text { Driver has informed control. } \\
\text { Occasional self-driving possible. }\end{array}$ & \\
\hline 3 & $\begin{array}{l}\text { Vehicle integrates } \\
\text { detection or response }\end{array}$ & $\begin{array}{l}\text { Driver ready to } \\
\text { take control. }\end{array}$ & $\begin{array}{l}\text { Partly legal and available on selected models } \\
\text { (i.e. Tesla Autopilot). }\end{array}$ \\
\hline 4 & $\begin{array}{l}\text { Vehicle fully } \\
\text { autonomous }\end{array}$ & $\begin{array}{l}\text { Driver takes control } \\
\text { in emergency. }\end{array}$ & $\begin{array}{l}\text { Legal in some areas in the USA for trial operations } \\
\text { (Uber, Waymo, etc). }\end{array}$ \\
\hline 5 & $\begin{array}{l}\text { Vehicle fully } \\
\text { autonomous }\end{array}$ & $\begin{array}{l}\text { No ability to drive needed. Cannot } \\
\text { be driven by humans. }\end{array}$ & $\begin{array}{l}\text { Legal in California since October 2018: } \\
\text { permission granted to Waymo. }\end{array}$ \\
\hline
\end{tabular}

Source: authors elaboration based on Hedlund, 2017. 
Levels 4 and 5 are tested worldwide (Hedlund, 2017).The real full-time driverless operations without human presence in the vehicle were not known to be legal and operating anywhere in the world (except for test operations, like in Chandler, Arizona or Mountain View, California in the USA). However, the situation is changing: on October 30, 2018 the Department of Motor Vehicles (DMV) of California has granted Waymo the first permit in the state to start fully driverless operations on public roads. Initially the geographic area of such tests was limited by the company to the "known" neighborhoods of San Francisco Bay area: Mountain View, Sunnyvale, Los Altos, Los Altos Hills, and Palo Alto.

Significant legislative and regulatory issues are still addressed to transportation authorities, car manufacturers, tech companies and other stakeholders. The pioneer of AVs regulation were the USA, where geographically, the first regulation regarding autonomous vehicles was passed in the state of Nevada in 2011 with Assembly Bill 511. In 2015, the six US states (California, Florida, Michigan, Nevada, North Dakota, Tennessee) and the District of Columbia passed legislation aimed at expressly regulating AVs, permitting, under certain conditions, the operation of self-driving cars in the context of "testing" (with California being the most advanced state now with more than 40 companies involved in testing almost 300 selfdriving cars). In the early 2018 over 30 states in the USA had enacted laws and executive orders related to advancing the testing or AV technology, with more states considering AVs legislation (McGihee, 2016).

\section{Literature review}

Despite the relative novelty of the research topic, due to high interest towards it, currently there is a significant amount of the existing literature on autonomous vehicles and possible implications of self-driving cars deployment, with socio-economic impact assessment of the technology, refereed as game changing and disruptive (UITP, 2016).

The analysis of the existing papers on AV topic figured out, that the majority of them thematically cover the following areas: impact of AVs on urban mobility (Fulton, 2018), evaluation of the general state of AV technology (Fraedrich, Lenz, 2016), socio-economic benefits, advantages, disadvantages and treads from AVs (Givoni, Thomopoulos, 2015; Dimitrakopoulos, 2017), safety, ethical and legal issues (Gogoll, Muller, 2016; Hedlund, 2017; Parker, Shandro, Cullen, 2017; McGehee, 2016), urban life and land use (Urmson, 2008, Heinrichs, 2016).

However, quite a few papers and reports provide the reader with the analysis of geography (KPMG,
2018) and diversification of the spatial structure of AV industry, in particular, of the AV startup ecosystem. No geographic analysis of AV startup ecosystem was carried out before, what proves the academic novelty of this article. Thus, the aim of this paper is to fill the existing gap.

Along with this, the results and findings can serve as basis for investment recommendations, as far as specific regulatory and socio-economic conditions define the certain geographic areas (countries, states, cities) with positive environment for investments into AV technology.

\section{Research methodology}

The geographic analysis presented in this article was based on the database of comprehensive list of major Al-powered companies (263 original startups plus 2 additional, 265 in total), politely provided to the author by Comet Labs, VC fund and platform for Al startups transforming foundational industries (Comet Labs, 2018). The spatial data on the startups location (headquarters geography was considered) was obtained via the search engine of Crunchbase, the portal that collects data on the world's most innovative companies (Crunchbase, 2018), and via additional information sources (i.e. companies web pages, Bloomberg data, etc.). Based on the quantitative and location data, spatial patterns of the startups distribution were analyzed, in general and with consideration of their types ( 8 in total, as presented in table 2).

Besides the existing academic literature, the official publications of international agencies, industry reports and policy papers (UITP, PwC Connectivity report, KPMG AVRI, lowa Department of Transportation, American Automobile Association, etc.) were analyzed in order to provide the reader with better understanding of current spatial, socio-economic and regulatory trends in the industry. The data obtained from KPMG autonomous vehicle readiness index (on 20 countries) was used to compare the existing innovative startup environment in the area of autonomous driving technologies (31 countries in total) with the overall industry environment.

The cartographic material provided in the article was based on the GIS database of the geographic structure of 265 startups, and was designed in ArcGIS software.

\section{The potential socio-economic impact of self-driving cars}

There is an ongoing discussion of how the developing game changing AV technology is going to affect the existing mobility patterns (taxi market, safety, traf- 
fic congestion, etc.), as well as related areas (urban planning, housing and retail sector, etc.) and various impact groups (users, governments and business). There are several possible inevitable changes in how self-driving cars will be used, which would be accompanied by altered attitudes to vehicles and driving (Fraedrich, Lenz, 2016). It is expected, that fully automated driving will entail a completely new urban transportation system, altering the trade-offs that households and urban residents make between choosing working and residential locations and daily mobility options (Heinrichs, 2016).

It is considered, that self-driving cars will help to optimize the traffic flow (but only when shared AV mobility is practiced), decrease the impact of human error and increase the overall safety on the roads (1.2 million worldwide a year die in automobilerelated deaths and $90 \%$ of the accidents are due to human error, UTIP, 2016). In financial terms, the anticipated potential of annual quantified benefits from the use of AVs has been estimated at US $\$ 1.3$ trillion for the USA, which will come from productivity gains (US\$507bn), reduction in accident costs (US\$488bn), fuel cost savings due to route optimization (US\$158bn), reduction in congestion related fuel loss (US\$11bn, Givoni, Thomopoulos, 2015). It is estimated that in 2030 various parts of autonomous driving ecosystem will deliver US \$1.8-2.8 trillion of revenue, with Alphabet's Waymo company, occupying $60 \%$ of the market. Among advantages of autonomous mobility, the following can be mentioned: smoother ride, reduction in car theft, higher speed limits, increased ergonomic effectiveness of the cabin, etc.; among disadvantages: loss of driving-related jobs, resistance from unions of professional drivers, loss of privacy, terrorism treads, software reliability issues, required costly changes in road infrastructure (Dimitrakopoulos, 2017). It is commonly agreed that significant technological, legal, regulatory, privacy, security and ethical aspects must be addressed and regulated before fully self-driving vehicles (levels 4-5) take to the roads.

\section{Factors, defining development of AV technologies}

In order to understand the spatial features of a certain technological progress, i.e. autonomous driving, it is important to understand the socio-economic and regulatory environment and the factors that may contribute to the spread of innovation or to be an obstacle on the way. For the progress of self-driving vehicles, it is crucially important to have a significant amount of innovative startups and companies with a wide range of opportunities to design, develop, and trial their new technologies. One of the internationally recognized indexes that evaluates the level of country's readiness for deployment of fully autonomous vehicles on the road is KPMGs Autonomous Vehicles Readiness Index (AVRI).

There are four main factors (or pillars, as described by KPMG), that define the preparedness and openness of various countries' for AVs technology: policy and legislation, technology and innovation, infrastructure and consumer acceptance. The index included 20 countries based on economic development and progress in adopting autonomous vehicles, with the Netherlands (with score 22.73), Singapore (26.08), USA (24.75), Sweden (24.73) and UK (23.99) on leading positions and Mexico (6.51) with India (6.14) on the bottom of the ranking list (see figure 1, KPMG, 2018).

The main conclusions of the KPMG AVRI report are that there is a high correlation between the index meanings and general socio-economic development of the country. The countries with the highest level of readiness have: a) governing authorities and institutions, willing to support $\mathrm{AV}$ development as well as to cooperate with manufacturers, establish partnerships and support stakeholders, companies and startups; b) good road and mobile network infrastructure (with LTE and $5 \mathrm{G}$ coverage at least); $\mathrm{c}$ ) positive environment for investors to finance the diffusion of innovations; d) large-scale testing supported by a significant industry presence (not only by car manufacturers). In addition, the complex system of AV technology development, that is considered as a game changer and a disruptive innovation (for instance, for taxi service or real estate market) requires not only support from decision-makers, manufacturers and financial circles, but a strongly positive public perception. After the incidents with Tesla's Autopilot in 2016 and Uber's driverless car in 2018, the decline in public support of AVs was recorded: in accordance with 2018 survey of American Automobile Association, 73\% U.S. drivers were afraid to ride in a fully automated vehicle (in comparison to $63 \%$ in 2017, AAA, 2018).

However, the comparison of 20 AVRI countries with the data of 265 startups located in 31 countries figured out some interesting spatial features, discussed in the next part of the article.

\section{Current geography of AV startup ecosystem}

The structural and geographic analysis of 265 startups, located in 31 countries figured out the following structural peculiarities and spatial features of their distribution. Firstly, it is important to understand the complexity of the AV-creating environment. According to Comet Labs industry map, there are eight types of the AV startups (with several sub-categories 
within every type), working on the following problem areas: services, infrastructure, in-car assistance and intelligence, safety, security, autonomy, sensors, materials and manufacturing, etc. (see table 2). The startups are relatively evenly distributed by types, with services being the leading type by share ( $16 \%$ of total), represented by companies working on route planning (Spatial), parking (CloudPark), car hailing (Uber), rental (Zipcar) solutions. The unique geographic feature, typical for all types of AV startups is that more than the half of them is located in the USA
( $57 \%$ on average, with numbers varying from $47 \%$ (incar intelligence and assistance) to $67 \%$ (intelligence manufacturing)).

Secondly, the geographic distribution of 265 AV startups, presented on figure 1, proved the correlation between the level of socio-economic development and attractiveness for innovative startups. That explains the leading position of the United States of America by the total ammount of AV startups, with 152 companies from the list, working on autonomous technologies headquatered in the country.

Table 2. Structure of major AV startups by type, 2018

\begin{tabular}{|c|c|c|c|}
\hline TYPE No. & Name of type & $\begin{array}{c}\text { Share (from } \\
\text { total), \% }\end{array}$ & $\begin{array}{c}\text { Leading country (with share from } \\
\text { total within the type), \% }\end{array}$ \\
\hline 1 & Services & 16 & USA (62) \\
\hline 2 & Safety and Security & 13 & USA (51) \\
\hline 3 & In-Car Intelligence and Assistance & 12 & USA (47) \\
\hline 4 & Autonomy & 15 & USA (56) \\
\hline 5 & Infrastructure plus Connected Car & 9 & USA (48) \\
\hline 6 & Intelligent Manufacturing & 11 & USA (67) \\
\hline 7 & Onboard sensors & 10 & USA (60) \\
\hline 8 & Specialty Vehicles & $\mathbf{1 0 0}$ & USA (65) \\
\hline Total & 265 start-ups & & USA (57) \\
\hline
\end{tabular}

Source: author's calculations based on Comet Labs data on start-ups.

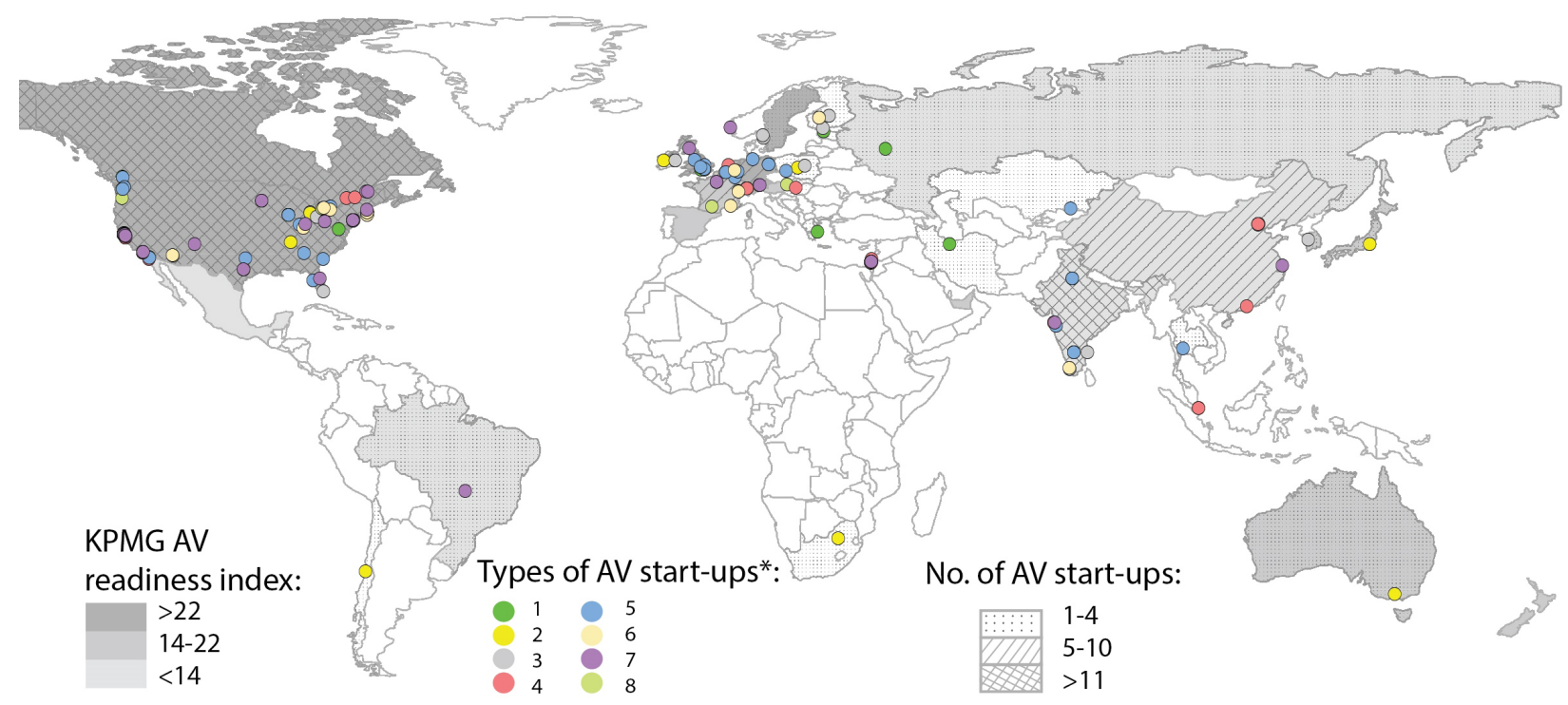

*Note: for the names of the types of AV startups, refer to table 2

Figure 1. Geographic structure of AV startup environment and readiness for autonomous cars, 2018

Source: author's elaboration based on KPMG (2018) and Comet Labs data (2017). 
The USA is ranked at the top of the technology and innovation pillar of the KPMG AVRI index, with the highest ratings on industry partnerships, R\&D hubs, AV technology company headquarters, investment, and World Economic Forum scores for technology availability and capacity for innovation (KPMG, 2018). The significand breakaway of the US from the rest of the world is supported by the share numbers of the other countries in the structure. Other countries on the top of the list by the number of AV startups are: Israel (6.4\%), India (5.3\%), Canada (4.5\%) United Kingdom (4.5\%) and China (2.6\%). With the growing affordability of technology (mainly due to decrease of prices on the market), the ammount of countries developing products for AV industries is increasing, covering not only developed, but also developing countries (i.e. Kazakhstan, Russia, Iran, Chile, Thailand, etc.).

Thirdly, geographically, 265 AV startups were headquartered in 142 cities, with $42.2 \%$ of them being the US cities, with San Francisco being the leading city by the share of the located AV startups (14\% of total). Based on AV startups location data, the following main technological Cores with the highest geographic concentration of AV companies can be distinguished: San Francisco Bay Area Core (the share of the startups, located here is more than $27 \%$ of total), US East Coast, Greater Toronto Area Core, Western European Core and Tel Aviv Area Core (figure 2).

\section{Summary}

This article highlighted some current structural, regulatory and spatial tendencies of the ongoing autonomous vehicles technology development and discussed some geographic aspects of spatial distribution of AV startup ecosystem. The spatial distribution of the disruptive AV technology may have an impact on various impact groups (consumer, governing agencies and businesses) via changes not only in the existing mobility patterns (taxi and ride-hailing market, safety, traffic congestion, etc.), but also in mobility-related practices (urban planning, job selection, housing and retail sector, etc.).

The current geography of autonomous readiness is dictated by such supporting or constraining internal or external socio-economic factors, such as development and availability of comfortable policy and legislation, available technology and innovation, developed infrastructure and high consumer acceptance. In order to improve country's' or city's level of readiness for AV technology deployment, high level of development of the mentioned pillars is strongly recommended.

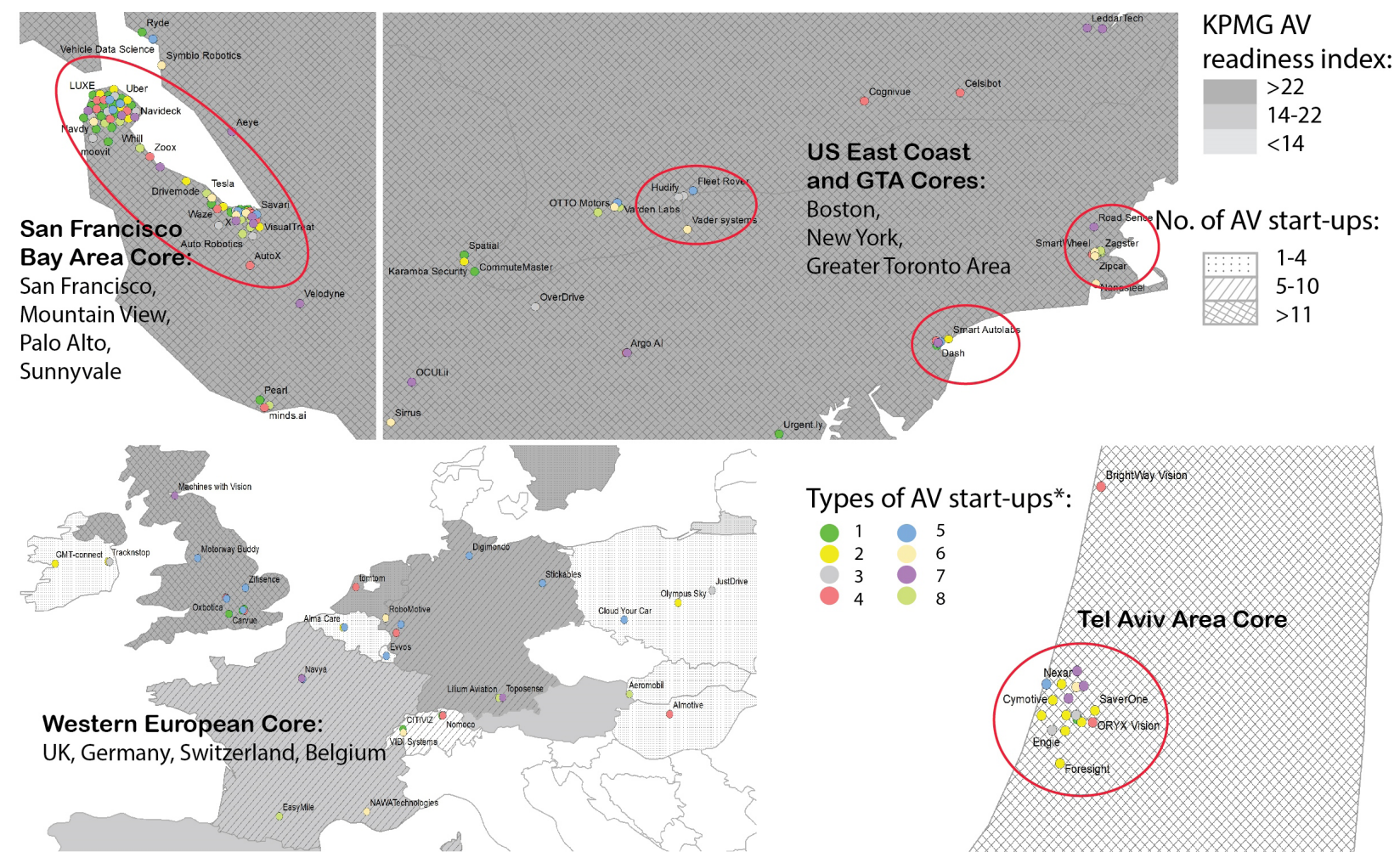

*Note: for the names of the types of AV startups, refer to table 2

Figure 2. The main technological Cores of AV startups

Source: author's elaboration based on KPMG (2018) and Comet Labs data (2017). 
Despite the fact that the Netherlands are the most ready country for fully self-driving cars to be deployed on roads (with the highest KPMG AVRI meaning), the USA is de-facto the global leader by the level of development of the market of innovative AV startups. There are more than $50 \%$ of the major AV companies located in the country, and with more than $27 \%$ of total amount concentrated within the attractive San Francisco Bay Area Core.

Finally, the key findings indicate that the diffusion of innovation, considered as disruptive and game changing, fueled by the increased availability of cheaper technology on the market may diversify the geography of AV research and physical trials and deployment, involving developing countries, such as Russia, Iran, Kazakhstan, etc.

\section{Acknowledgements}

Author wants to express gratitude to the representatives of Comet Labs (https://cometlabs.io/), particularly to the brand Director Derek Embry who was very kind to give the permission to use the list of AV startups. In addition, I want to thank the talented representatives of the Department of Geography from Chair of Economic and Social Geography A. Mazan and E. Berdnik for some support and assistance with data procession in the process of preparing this article.

\section{References}

American Automobile Association, 2018, Vehicle Technology Survey - Phase Illb. Fact Sheet, American Automobile Association, USA

Comet Labs, 2017, 263 Self-Driving Car Startups to Watch, Comet Labs, USA

https://blog.cometlabs.io/263-self-driving-car-startupsto-watch-8a9976dc62b0 [09.11.2018] Crunchbase, 2018, Discover innovative companies and the people behind them, Crunchbase Inc., USA, https://www. crunchbase.com/ [09.11.2018]
Dimitrakopoulos G., 2017, The Future: Towards Autonomous Driving, Current Technologies in Vehicular Communications, Springer International Publishing AG

Fraedrich E., Lenz B., 2016, Taking a Drive, Hitching a Ride: Autonomous Driving and Car Usage, M. Maurer et al. (eds.), Autonomous Driving, Berlin, 665-670

Fulton L., et al., 2018, Three Revolutions in Urban Transportation, ITDP, UC Davis, USA. Access mode: https:// www.itdp.org/publication/3rs-in-urban-transport/ [08.11.2018]

Givoni M., Thomopoulos N., 2015, The autonomous cara blessing or a curse for the future of low carbon mobility? An exploration of likely vs. desirable outcomes, European Journal of Futures Research, 3 (14)

Gogoll J., Muller J. F., 2016, Autonomous Cars: In Favor of a Mandatory Ethics Setting, Springer Science+Business Media, Dordrecht

Hedlund J., 2017, Autonomous Vehicles Meet Human Drivers: Traffic Safety Issues for States, Governors Highway Safety Association, Washington, DC

Heinrichs D., 2016, Autonomous Driving and Urban Land Use, M. Maurer et al. (eds.), Autonomous Driving, Berlin, 213-229

KPMG International, 2018, Autonomous Vehicles Readiness Index, KPMG International Cooperative ("KPMG International")

McGehee D., 2016, Review of Automated Vehicle Technology: Policy and Implementation Implications, University of lowa, DOT lowa, lowa City

Parker N., Shandro A., Cullen E., 2017, Autonomous and connected vehicles: navigating the legal issues, Allen \& Overy $L L P$, London

PwC, 2016, Connected Car Report 2016. Opportunities, risk, and turmoil on the road to autonomous vehicles, Strategy \&, PwC

UITP, 2018, Autonomous vehicles: A Potential Game Changer for Urban Mobility, Policy Paper, International Association of Public Transport, Brussels

Urmson C., et al., 2008, Autonomous Driving in Urban Environments: Boss and the Urban Challenge, Journal of Field Robotics 25(8), Wiley Periodicals, Inc. 